\title{
Intercomparison of Mixing Layer Heights from the National Weather Service Ceilometer Test Sites and Collocated Radiosondes
}

\author{
MiCHEAL Hicks \\ National Weather Service, Sterling, Virginia \\ BELAY DEMOZ \\ University of Maryland, Baltimore County, Baltimore, Maryland \\ KEVIN VERMEESCH \\ Global Science and Technology, Inc., Greenbelt, Maryland \\ DENNIS ATKINSON \\ National Weather Service, Silver Spring, Maryland
}

(Manuscript received 6 April 2018, in final form 12 October 2018)

\begin{abstract}
A network of automated weather stations (AWS) with ceilometers can be used to detect sky conditions, aerosol dispersion, and mixing layer heights, in addition to the routine surface meteorological parameters (temperature, pressure, humidity, etc.). Currently, a dense network of AWSs that observe all of these parameters does not exist in the United States even though networks of them with ceilometers exist. These networks normally use ceilometers for determining only sky conditions. Updating AWS networks to obtain those nonstandard observations with ceilometers, especially mixing layer height, across the United States would provide valuable information for validating and improving weather/climate forecast models. In this respect, an aerosol-based mixing layer height detection method, called the combined-hybrid method, is developed and evaluated for its uncertainty characteristics for application in the United States. Four years of ceilometer data from the National Weather Service Ceilometer Proof of Concept Project taken in temperate, maritime polar, and hot/arid climate regimes are utilized in this evaluation. Overall, the method proved to be a strong candidate for estimating mixing layer heights with ceilometer data, with averaged uncertainties of $237 \pm 398 \mathrm{~m}$ in all tested climate regimes and $69 \pm 250 \mathrm{~m}$ when excluding the hot/arid climate regime.
\end{abstract}

\section{Introduction}

The turbulence within the atmospheric mixing layer (ML), also known as the atmospheric boundary layer, controls the exchanges of heat, moisture, momentum, trace gases, and aerosols from the surface to the atmosphere and vice versa (Seibert et al. 2000). Its height, defined as the top of the lowest layer of the atmosphere where these exchanges between the surface and upper troposphere mix into it in less than 1 or $2 \mathrm{~h}$ (Luo et al. 2014), is directly related to the intensity of ML turbulence (Liu and Liang 2010). Therefore, it can be used as a scalar to constrain ML parameterization methods in

Corresponding author: Micheal Hicks, micheal.m.hicks@noaa.gov atmospheric models to help improve weather and climate predictions (Yang et al. 2017). Unfortunately, a high-density network of ML height observations within the United States does not exist, even though remote sensing technologies, such as ceilometers and lidars, show feasibility to accomplish this task (Hicks et al. 2015; Emeis et al. 2008).

In 2012, the National Weather Service (NWS) initiated a Ceilometer Proof of Concept Project to evaluate the observing potential of ceilometers (Atkinson et al. 2017). The NWS installed several ceilometers around the United States near automated weather stations (AWS) and also leveraged ceilometer data from partner organizations to form Proof of Concept Test Sites. The Proof of Concept Test Sites collected ceilometer-attenuated 
backscatter profile data for four years (2013-16; Atkinson et al. 2017). The objective of the Ceilometer Proof of Concept Project was to show the capabilities of ceilometers beyond detecting sky conditions. This paper utilizes the dataset to evaluate the performance of an aerosolbased ML height detection algorithm, in anticipation of ceilometer backscatter data at AWSs being made available for user consumption in the near future.

Hicks et al. (2015) used a consortium of automated aerosol-based detection methods [i.e., hybrid, hybridlowest (H-L), 1D Haar wavelet covariance transform (WCT), and error function ideal-profile detection methods] to retrieve ML height and to provide guidance on which method to use per atmospheric stability condition. The following analysis utilizes this guidance and produces an optimized algorithm and evaluates its performance in three distinct U.S. climate regimes: temperate, maritime polar, and hot/arid.

In the subsequent sections the following is presented: Section 2, the climatologically representative test sites and instrumentation used; section 3, the ML height retrieval method and evaluation methodology; section 4, the results; and section 5, a summary.

\section{Test sites and instrumentation}

The Proof of Concept Test Sites utilized the Vaisala model CL31 ceilometer. This remote sensing lidar system is an automated all-weather device with a $10-\mathrm{kHz}$ pulsed indium gallium arsenide (InGaAs) diode laser. It transmits at $910 \mathrm{~nm}$ with a pulse width of $110 \mathrm{~ns}$ and energy of $1.2 \mu \mathrm{J}$ per pulse. It has a silicon avalanche photodiode detector and retrieves attenuated backscatter profiles from 0 to $7700 \mathrm{~m}$ AGL with variable spatial resolution. For this study the instrument was configured to provide a 20-m spatial resolution and was polled every $30 \mathrm{~s}$ and downsampled, by block averaging, to 10-min temporal resolution.

Collocated ceilometer and radiosonde observations were obtained from the NWS Proof of Concept Test Sites. The data were collected in areas of diverse U.S. climate conditions. The geographical regions of interest in this study are the mid-Atlantic, southern Midwest, polar, and Southwest. The mid-Atlantic and southern Midwest datasets were combined to represent the temperate climate regime. Descriptions of the test sites representing the temperate, maritime polar, and hot/arid climate regimes are given below.

\section{a. Temperate continental climate}

The temperate climate regime was made up of the Sterling Field Support Center (SFSC) and the Howard University Beltsville Research Campus (HUBRC) in the mid-Atlantic region of the United States, and the Atmospheric Radiation Measurement (ARM) Southern Great Plains (SGP) campus in the southern Midwest of the United States.

The NWS SFSC $\left(38.973^{\circ} \mathrm{N},-77.488^{\circ} \mathrm{E}\right)$ is located in a suburban community in Sterling, Virginia, at $88 \mathrm{~m}$ MSL and roughly $48 \mathrm{~km}$ west-northwest of Washington, D.C. It has cool winters and warm humid summers with an average annual precipitation amount of $41.5 \mathrm{in}$. The site's ceilometer backscatter data were utilized from March 2013 to December 2016. In addition, the NWS Baltimore/Washington forecast office (LWX) is collocated with the SFSC and their twice daily (0000 and 1200 UTC) radiosoundings of the Lockheed Martin Sippican model LMS6 radiosonde were used in the analysis. Also, twice daily (0000 and 1200 UTC) radiosonde observations from SFSC's Vaisala model AS-14 Autosonde Launcher from 2015 through 2016 were utilized. All sounding observations at SFSC used 2-s temporal resolution.

The HUBRC $\left(39.054^{\circ} \mathrm{N},-76.877^{\circ} \mathrm{E}\right)$ is located in Beltsville, Maryland, in a suburban area at $52 \mathrm{~m}$ MSL and roughly $15 \mathrm{~km}$ northeast of Washington, D.C. It has climate similar to that of the SFSC. The HUBRC is located in a coastal plain region, while the SFSC is located in the Piedmont of the Blue Ridge Mountains. Both locations are dominated by continental polar and maritime tropical air masses and occasional maritime polar air masses. The HUBRC ceilometer data were used for this analysis from February 2013 to November 2014 with soundings of the Vaisala model RS92-SGP radiosonde conducted at least weekly.

The ARM SGP campus is located near Lamont, Oklahoma $\left(36.605^{\circ} \mathrm{N},-97.485^{\circ} \mathrm{E}\right)$, in a rural environment at $320 \mathrm{~m}$ MSL. It has similar climate and dominate air masses as the other temperate climate sites with annual precipitation totals of $36.5 \mathrm{in}$. The SGP ceilometer backscatter profile data were used here from January 2013 to December 2016 with soundings of the Vaisala model RS92-SGP radiosonde conducted four times daily (0530, 1130, 1730, and 2330 UTC).

\section{b. Polar climate}

The ARM's North Slope of Alaska (NSA) campus is located at Barrow, Alaska (now known as Utqiagvik; $71.323^{\circ} \mathrm{N},-156.616^{\circ} \mathrm{E}$ ), near sea level along the coast of the Beaufort Sea. It has mild tundra climate conditions with annual precipitation totals of $4.53 \mathrm{in}$. It is the northernmost city of the United States and is dominated by maritime polar, continental polar, and continental arctic air masses. The NSA's ceilometer backscatter and Vaisala model RS92-SGP radiosounding data were used here from January 2013 to December 2016. The radiosonde 

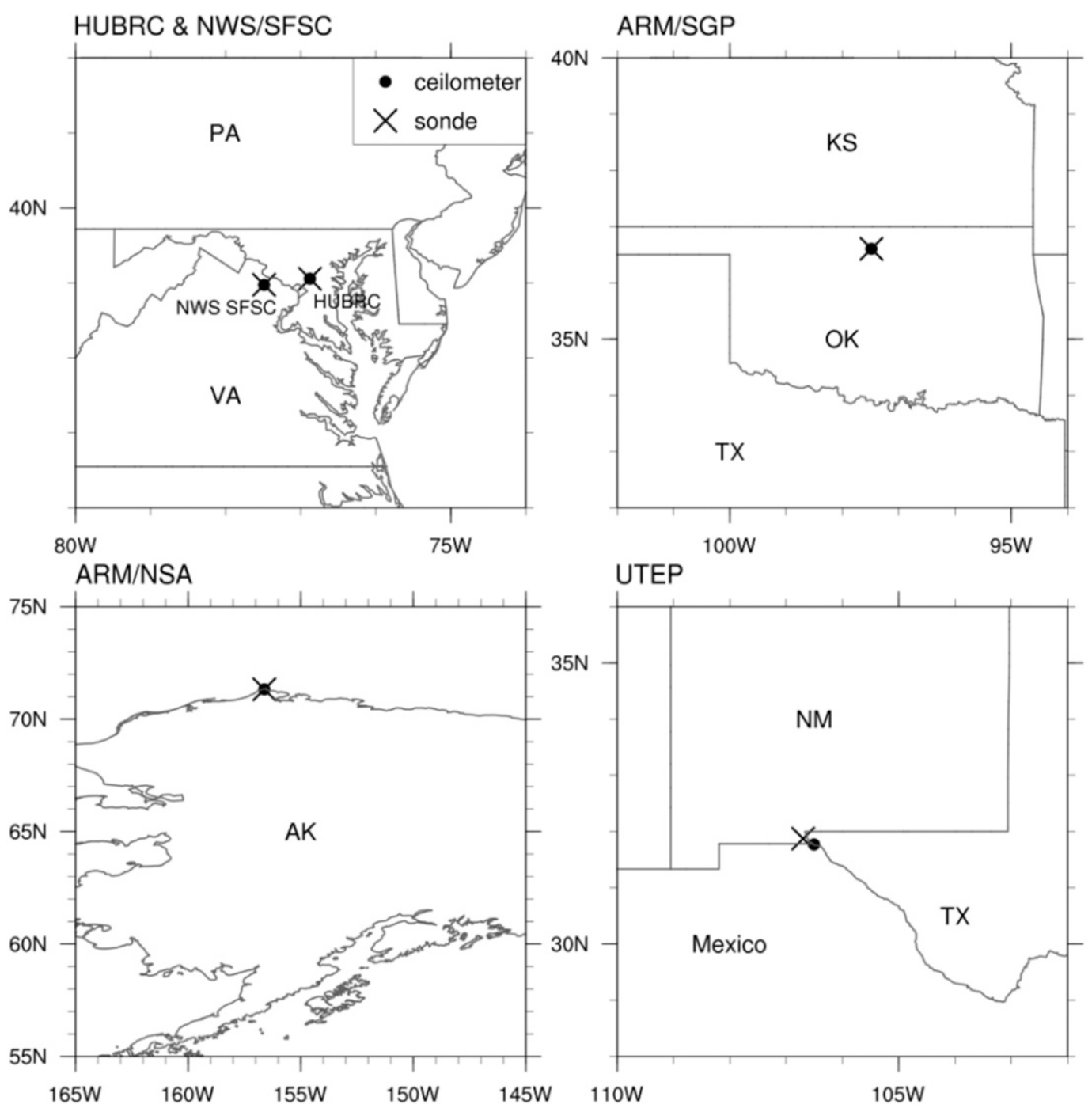

FIG. 1. Geographical locations of the test sites and locations of the ceilometer and radiosonde release points. The hot/arid climate regime (UTEP) is the only climate regime with the ceilometer and radiosonde locations not collocated. The radiosonde release point is roughly $25 \mathrm{~km}$ northwest (in Santa Teresa, NM) of the ceilometer location in El Paso.

observations were taken twice daily (0530 and 1730 UTC) with a 2-s temporal resolution.

\section{c. Hot/arid climate}

The University of Texas at El Paso (UTEP; $31.770^{\circ} \mathrm{N}$, $\left.-106.505^{\circ} \mathrm{E}\right)$ is located in the southwestern region of the United States in El Paso, Texas, at $1170 \mathrm{~m}$ MSL. It has a climate of dry continental with annual precipitation totals of $9.71 \mathrm{in.} \mathrm{Its} \mathrm{dominating} \mathrm{air} \mathrm{masses} \mathrm{include} \mathrm{continental}$ tropical and continental polar. The NWS El Paso Forecast Office $\left(\mathrm{EPZ} ; 31.873^{\circ} \mathrm{N},-106.698^{\circ} \mathrm{E}\right)$ is $25 \mathrm{~km}$ northwest of the university and conducts radiosoundings twice daily at synoptic hours with the LMS6 radiosonde. The LMS6 radiosonde outputs data with a 2 -s temporal resolution.
The UTEP ceilometer backscatter data were used from March 2015 to December 2016. To express the distance between this climate regime's ceilometer and radiosonde release locations, Fig. 1 shows all the test sites' locations and their distance from the radiosounding release point.

\section{Methodology}

The ML height can be determined by the detection of a significant gradient in a vertical profile of aerosol density as a by-product of the ML turbulence, with the more uniform densities existing within the ML. Therefore, a gradient-based algorithm can be applied to a ceilometer's observation of attenuated aerosol 
NWS EL Paso, 01AUG2015 11:05 UTC
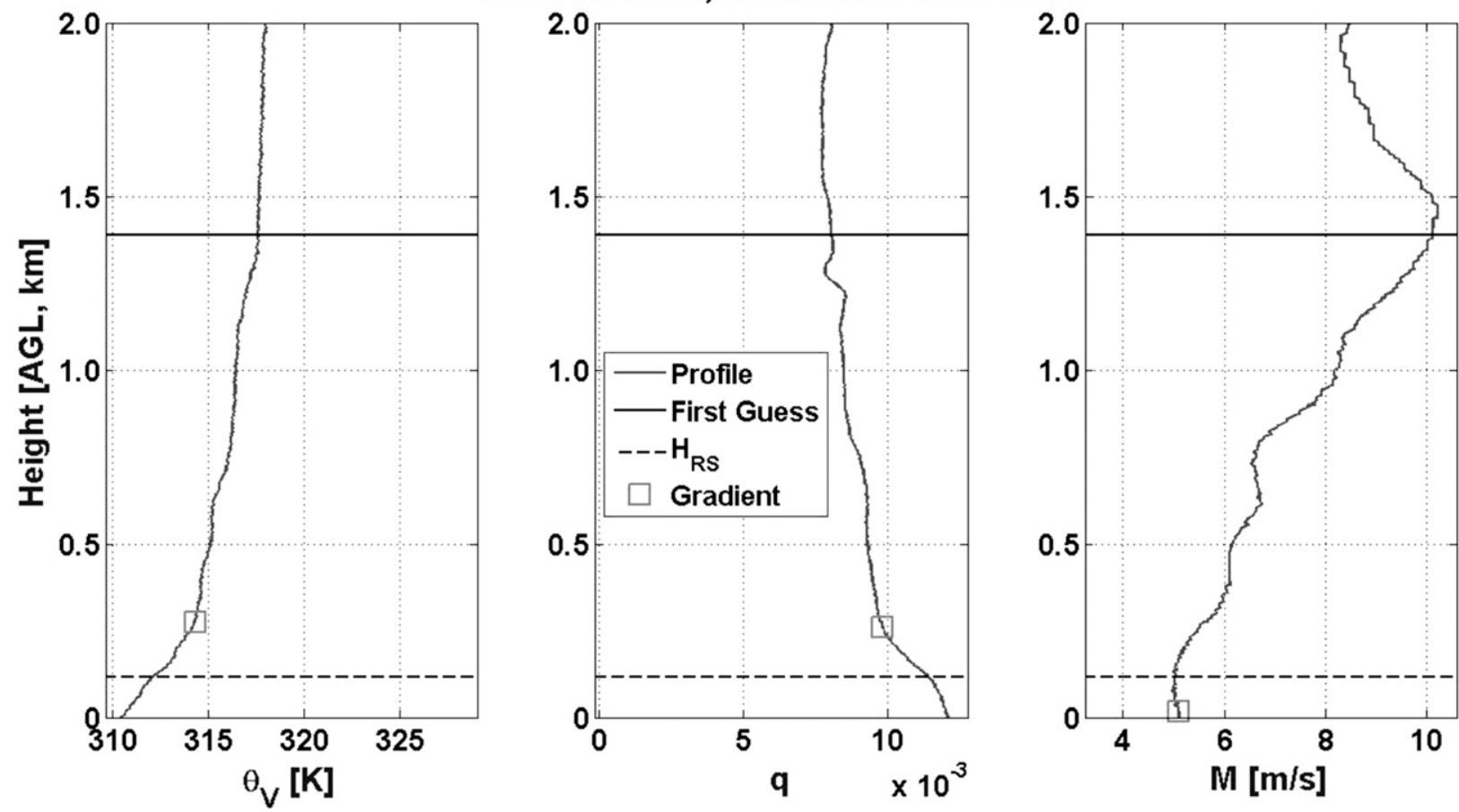

FIG. 2. Radiosounding of (left) virtual potential temperature, (middle) specific humidity, and (right) wind speed conducted at the NWS El Paso. This figure demonstrates how the $H_{\mathrm{RS}}$ method is quality controlled for determining ML height. Here is an example of a stable ML and the first guess determined by Espy's LCL height equation. The dashed line displays the height determined by the $H_{\mathrm{RS}}$ method. This $H_{\mathrm{RS}}$ value will be used in the comparison analysis, since at least one of the ML height derivations by the gradient methods agree within $\pm 250 \mathrm{~m}$.

backscatter for ML height detection. This study utilizes the WCT (Davis et al. 2000) and H-L (Hicks et al. 2015) aerosol-based ML height detection algorithms for this purpose. Hicks et al. (2015) found that the WCT method performed best during unstable and near-neutral stability conditions, while the H-L method performed best during stable conditions. The two methods are applied in this respect for optimization with calculations of the lifting condensation level (LCL) height being used as a first-guess estimate for ML height (Lawrence 2005). Also, this algorithm uses the time of day and solar elevation angle as proxies to determine atmospheric stability condition as discussed in Hicks et al. (2015). This algorithm is called the combined-hybrid $\left(H_{C}\right)$ method. The $H_{C}$ method is applied to the Proof of Concept Test Sites' dataset and intercompared to coincident radiosonde-based ML height $\left(H_{\mathrm{RS}}\right)$ estimates, as done by Hicks et al. (2015). The $H_{C}$ method is applied to 10-min averaged ceilometer backscatter profiles and compared to $H_{\mathrm{RS}}$ observations that have a timestamp roughly $15 \mathrm{~min}$ prior to the $H_{C}$-centered time stamp. This allows ample time for the sounding to reach the ML height while ascending approximately at $5 \mathrm{~m} \mathrm{~s}^{-1}$.
The bulk Richardson method (Seidel et al. 2010) is applied to radiosonde data to determine $H_{\mathrm{RS}}$ via an estimate of atmospheric turbulence. Empirical critical bulk Richardson number values of $0.25,0.05$, and 0.01 are used to identify the top of the ML for stable, nearneutral, and unstable atmospheric stability conditions, respectively (Hicks et al. 2015). These atmospheric stability conditions are determined by the average of lowaltitude (below $200 \mathrm{~m}$ AGL) bulk Richardson values. The ML stability condition is considered unstable if the averaged low-altitude bulk Richardson value is less than -0.01 , near neutral if between or equal to -0.01 and 0.01 , and stable if greater than 0.01 . In addition, stability conditions are used to stratify the intercomparison cases and to isolate the $H_{C}$ method's strengths and weaknesses. The $H_{\mathrm{RS}}$ method is quality controlled by using the radiosounding's maximum gradient of virtual potential temperature and minimum gradients of specific humidity and wind speed to determine ML heights (see Fig. 2). The $H_{\mathrm{RS}}$ estimates that disagreed with all of the gradient methods by more than $0.25 \mathrm{~km}$ were discarded from the analysis.

In addition to stability, the $H_{C}$ data are evaluated by aerosol optical depth (AOD), sky cover, wind 
TABLE 1. Sample size $(N)$, consistency rates (Co), mean bias $(\mu)$, and root-mean-square error (RMSE) of $H_{C-} H_{\mathrm{RS}}$. This comparison is categorized by atmospheric stability and aerosol loading [high loading (HL) is $>0.5$, low loading (LL) is $<0.1$, and medium loading (ML) is in between]. Comparisons for the respective sites were stratified by aerosol loading conditions only if the ceilometer and aerosol loading observing stations were less than $25 \mathrm{~km}$ apart. Therefore, comparisons were not stratified by aerosol loading for SFSC and UTEP. The Co parameter provides the percentage of differences that are less than $\pm 300 \mathrm{~m}$. In addition, the overall performance of the components (WCT and H-L) of the $H_{C}$ method is included in the table.

\begin{tabular}{|c|c|c|c|c|c|c|c|c|c|c|c|c|}
\hline & \multicolumn{4}{|c|}{ Temperate SFSC, HUBV, SGP } & \multicolumn{4}{|c|}{ Maritime polar NSA } & \multicolumn{4}{|c|}{ Hot and arid UTEP } \\
\hline & $N$ & Co $(\%)$ & $\mu(\mathrm{m})$ & $\operatorname{RMSE}(\mathrm{m})$ & $N$ & $\operatorname{Co}(\%)$ & $\mu(\mathrm{m})$ & $\operatorname{RMSE}(\mathrm{m})$ & $N$ & Co $(\%)$ & $\mu(\mathrm{m})$ & $\operatorname{RMSE}(\mathrm{m})$ \\
\hline All $\left(H_{C}\right)$ & 1671 & 80 & 73 & 325 & 1042 & 93 & 65 & 174 & 185 & 65 & 321 & 696 \\
\hline Unstable & 134 & 76 & 9 & 421 & 35 & 83 & -119 & 198 & 19 & 5 & 297 & 1014 \\
\hline Stable & 856 & 84 & 167 & 277 & 505 & 90 & 166 & 202 & 132 & 75 & 336 & 626 \\
\hline Neutral & 681 & 74 & -33 & 357 & 502 & 97 & -25 & 139 & 34 & 62 & 276 & 733 \\
\hline $\mathrm{HL}$ & 70 & 73 & 142 & 284 & 17 & 94 & 122 & 174 & - & - & - & - \\
\hline ML & 71 & 75 & 31 & 292 & 34 & 74 & 133 & 270 & - & - & - & - \\
\hline LL & 115 & 84 & 84 & 286 & 54 & 78 & 129 & 250 & - & - & - & - \\
\hline All (WCT) & 1671 & 75 & 186 & 401 & 1042 & 92 & 51 & 179 & 185 & 54 & 561 & 987 \\
\hline All (H-L) & 1671 & 77 & 51 & 334 & 1042 & 93 & 20 & 168 & 185 & 68 & 302 & 740 \\
\hline
\end{tabular}

speed, season, and time of day for the three climate regimes. The performance results of the $H_{C}$ method did not show a strong dependence on these conditions. Therefore, the results of the $H_{C}$ method under these conditions, except AOD, will not be further discussed but provided in the appendix as a reference for users of the algorithm. Its performance under AOD conditions is presented because, when oversimplifying the backscatter process, it has implications on the expected data quality of the ceilometer backscatter signal. For the sake of this study, it is assumed that higher AOD implies higher particulate scattering and therefore higher signal strength. The National Aeronautics and Space Administration (NASA) Aerosol Robotic Network (AERONET) was used to obtain observations of AOD. The AERONET sites within $25 \mathrm{~km}$ of a test site were used to characterize aerosol loading conditions for that site (Holben et al. 1998). The AERONET sites used include the Goddard Space Flight Center (GSFC) in Greenbelt, Maryland $\left(38.992^{\circ} \mathrm{N},-76.839^{\circ} \mathrm{E}\right)$, for the HUBRC test bed site; the collocated SGP site; and the collocated NSA site. Unfortunately, the hot/arid climate regime test site at UTEP did not have an AERONET site within $25 \mathrm{~km}$ and no aerosol loading analysis was performed. The AOD dataset used from the AERONET database was cloud-screened version 3, level 1.5 at $870 \mathrm{~nm}$ (NASA 2017).

\section{Results}

\section{a. Intercomparison}

Table 1 provides the results of the comparison of the $H_{C}$ and $H_{\mathrm{RS}}$ methods. The $H_{C}$ method compared well with the reference results of the $H_{\mathrm{RS}}$ method in the temperate and maritime polar climate regime with an average error of $69 \pm 250 \mathrm{~m}$. This is a particularly good result, as the best that can be expected between two instruments observing ML height is on the order of $\pm 200 \mathrm{~m}$ when considering atmospheric variability and system bias (Weldegaber et al. 2011). In the hot/arid climate regime, the intercomparison proved to be more of a challenge for the $H_{C}$ method. Table 1 breaks down the performance of the $H_{C}$ method by stability and aerosol load conditions. In temperate climate, the $H_{C}$ method showed a dependence on stability with the least and greatest intercomparison errors occurring during stable and unstable conditions, respectively. The average errors for those conditions were $167 \pm$ $277 \mathrm{~m}$ and $9 \pm 421 \mathrm{~m}$ for the stable and unstable conditions, respectively. The larger uncertainty of the unstable condition is related to the ceilometer's backscatter data losing signal strength with altitude, which commonly occurs in ML with large convective eddies and heights. The intercomparison results did not show a dependence on aerosol loading in temperate conditions for the $H_{C}$ method. In the maritime polar climate, the $H_{C}$ method tended to slightly overestimate $H_{\mathrm{RS}}$ in stable atmospheric conditions and slightly underestimate it in neutral and unstable atmospheric conditions. Its performance showed very little dependence on aerosol loading amount and has an average error of $65 \pm 174 \mathrm{~m}$

The $H_{C}$ method showed significant overestimation in the hot/arid climate regime relative to the $H_{\mathrm{RS}}$ method. This is partially due to the ML heights being routinely large (over $4000 \mathrm{~m}$ ) and, as with the temperate climate regime, larger discrepancies exist as a result of a decrease in the signal strength of the backscatter profile 


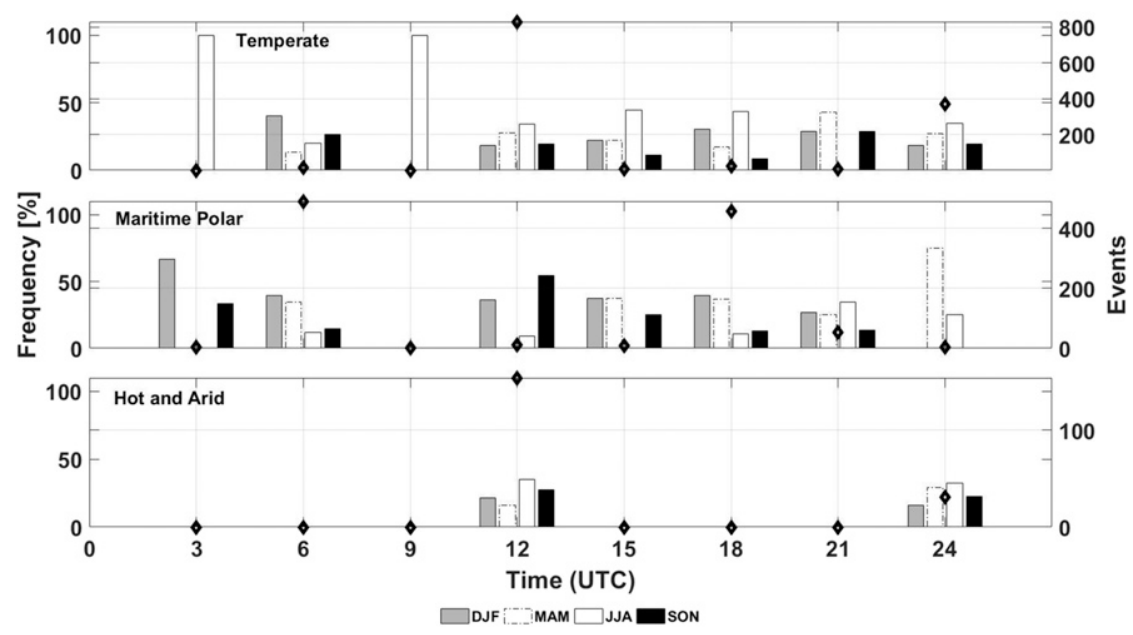

FIG. 3. Diurnal distribution of ML height intercomparison results of the $H_{C}$ method and the $H_{\mathrm{RS}}$ reference method for each climate regime of the study from 2013 to 2016 . The results are stratified by the meteorological seasonal months of winter (DJF), spring (MAM), summer (JJA), and autumn (SON). The diamond markers represent events, and the histogram bars represent percent of seasonal occurrences.

with altitude. Also, large MLs can increase the likelihood of spatial comparison errors occurring, especially in late afternoon/evening periods, when its top is more ambiguous, and the evening time period is when most intercomparisons occurred for this climate regime's neutral and unstable stability conditions (see Fig. 3). In addition, the $H_{C}$ method compared worst here in stable conditions relative to the other climate regimes. This is partially the result of the sounding and ceilometer test sites not being as collocated as the other sites and surface conditions having more of a local effect on the height of stable MLs. This result also shows the limitation of the $H_{C}$ method's first-guess estimate. The first guess, as discussed by Hicks et al. (2015), is determined by calculating the LCL height with Espy's equation (Lawrence 2005). Observations of surface and dewpoint temperatures required for this estimate were taken from nearby AWSs [i.e., SFSC (Washington Dulles International Airport, Virginia; KIAD), HUBRC (College Park, Maryland; KCGS), SGP (Blackwell, Oklahoma; KBKN), NSA (Barrow; Wiley Post-Will Rogers Memorial Airport; PABR), and UTEP (El Paso International Airport; KELP)]. Espy's equation assumes dry adiabatic cooling conditions, and the dry and warm conditions of UTEP climate are nonideal and cause great overestimation of the first-guess ML height of the algorithm, especially during spring months, which often have very large dewpoint depressions (less than $0.3 \mathrm{in}$. of precipitation per spring month). For example, averaged first-guess estimates in stable conditions were 820 and $625 \mathrm{~m}$ for the temperate and maritime polar climate regimes, respectively, compared to $1537 \mathrm{~m}$ for the hot/arid climate regime; and an averaged $2116 \mathrm{~m}$ for just the spring months.

The components of the $H_{C}$ method, WCT and H-L, were also applied to this dataset with the application of the first-guess estimate to contrast with the performance of the $H_{C}$ method. Similar to the results of Hicks et al. (2015), the WCT method performed the best in unstable and neutral conditions, and the H-L method performed the best in stable conditions relative to each other. An exception to this behavior was identified in the hot/arid climate regime. This occurred as a result of the overestimating tendency of the first-guess estimate in this climate regime; the H-L method provided the overall best results in all stability conditions, as the method looks for the lowest significant gradient to represent $\mathrm{ML}$ height. These results can also be found in Table 1.

\section{b. Diurnal mixing layer heights}

Figure 4 shows the seasonal means of diurnal ML heights determined by the $H_{C}$ method applied to the Proof of Concept Test Sites for the temperate, maritime polar, and hot/arid climate regimes. Full-day datasets from the $H_{C}$ method were used to estimate diurnal ML heights on days where there were an intercomparison made with the $H_{\mathrm{RS}}$ method. The average seasonal diurnal ML height estimates for the temperate climate condition are very consistent with past studies (e.g., Liu and Liang 2010); with the summer, being the most convective, producing the highest ML heights and winter the lowest, and the nocturnal ML height being much less than those during the midday. It compares well to the seasonally average characteristics of the diurnal ML 


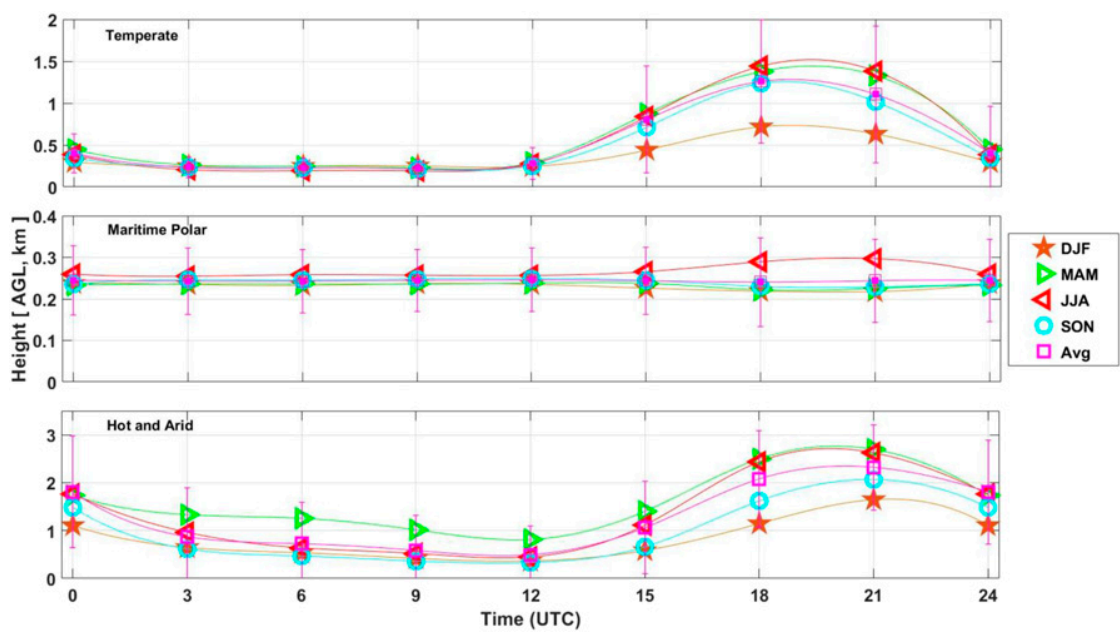

FIG. 4. Seasonal and diurnal 3-h averaged ML heights determined by the $H_{C}$ method for the climate regimes of this study from 2013 to 2016. The diurnal ML heights include full-day datasets from the $H_{C}$ method, where there is at least one $H_{\mathrm{RS}}$ comparison made. The results are stratified by the meteorological seasonal months of winter (DJF), spring (MAM), summer (JJA), and autumn (SON).

heights observed by the limited $H_{\mathrm{RS}}$ method diurnal dataset. The $H_{C}$ observations in the maritime polar climate regime did not show much diurnal structure or seasonal dependence with its ML heights falling between 200 and $400 \mathrm{~m}$ on average. The $H_{\mathrm{RS}}$ method determined average seasonal ML heights of 214 and $203 \mathrm{~m}$ at 0530 and 1700 UTC, respectively, which supports the $H_{C}$ method's finding of a lack of a diurnal structure. This climate regime has little ML height diurnal structure as a result of low solar heating and consequently year-round low solar elevation angles. The summer months show some ML growth when transitioning into midday hours, when more solar heating is available. The hot/arid climate regime has seasonal-dependent diurnal ML height structures with large ML heights (up to $4400 \mathrm{~m}$ ). The spring months unrealistically provide the largest ML heights throughout the diurnal cycle. This result ties back to the limitation of the $H_{C}$ method's first-guess estimate of ML height, as discussed previously. The $H_{\mathrm{RS}}$ method's averaged spring ML diurnal heights are 1622 and $86 \mathrm{~m}$ at 0000 and $1200 \mathrm{UTC}$, respectively, while the $H_{C}$ method is 1730 and $810 \mathrm{~m}$ at the same respective times. Its first guess has a large overestimate bias in extreme hot and dry conditions at night. The other seasonal diurnal averages in this climate regime agree with the $H_{\mathrm{RS}}$ method within $\pm 300 \mathrm{~m}$ for the 0000 and 1200 UTC observation periods. In addition, the averaged spring midday $H_{C}$ observation at 1800 UTC being larger than the summer's in this climate regime is believed to be an artifact of inadequate and unequal sampling of summer and spring cases. There are 42 and
70 daily cases for summer and spring, respectively, included in the diurnal averages.

\section{Summary}

An AWS network providing attenuated backscatter profile data from a ceilometer has the potential to detect aerosol dispersion and ML heights. This study evaluates the $H_{C}$ method's ability to detect ML heights from ceilometer data in temperate, maritime polar, and hot/arid climate regimes. It shows that the $H_{C}$ method compares satisfactory to ML heights derived by collocated radiosoundings for the temperate and maritime polar climate regimes, with an average error of $69 \pm$ $250 \mathrm{~m}$. The ML heights of the hot/arid climate regime proved to be more of a challenge for the intercomparison because of the spatial separation of the radiosounding release point and the ceilometer test site, large ML depth, and its climatic hot and dry conditions. The poor performance of the $H_{C}$ method in this climate regime showed the importance of the first-guess estimate when deriving ML heights. A method to provide a better first guess of ML heights in all climate regimes, especially in the hot/arid regime, will greatly improve the performance of the $H_{C}$ method. It may be best for the H-L method to be used in hot/arid conditions whenever the first-guess method is unrealistically high, which will take some a priori knowledge of the behavior of the ML being evaluated.

An AWS network with ceilometers shows great potential for ML height detection and will be a great asset 
TABLE A1. This table includes additional results for the comparison between the $H_{C}$ method and the $H_{\mathrm{RS}}$ reference method. Sample size $(N)$, consistency rates (Co), mean bias $(\mu)$, RMSE, and average ML heights of $H_{\mathrm{RS}}$ for $H_{C-} H_{\mathrm{RS}}$ are provided. The additional areas of analysis include season, diurnal period, wind speed, and cloud cover. These results are to be used by users of the algorithm and researchers for validation and comparison studies.

\begin{tabular}{|c|c|c|c|c|c|c|c|c|c|c|c|c|c|c|c|}
\hline \multirow[b]{2}{*}{$H_{C-} H_{\mathrm{RS}}$} & \multicolumn{5}{|c|}{ Midlatitude } & \multicolumn{5}{|c|}{ Maritime polar } & \multicolumn{5}{|c|}{ Hot/arid } \\
\hline & $N$ & $\mathrm{Co}$ & $\mu$ & RMSE & $\overline{M L} \bar{z}$ & $N$ & $\mathrm{Co}$ & $\mu$ & RMSE & $\operatorname{ML} \bar{z}$ & $N$ & $\mathrm{Co}$ & $\mu$ & RMSE & $\overline{\mathrm{ML}} \bar{z}$ \\
\hline All & 1671 & 0.796 & 0.073 & 325 & 0.249 & 1042 & 0.930 & 0.065 & 0.174 & 0.173 & 185 & 0.654 & 0.321 & 0.696 & 0.378 \\
\hline all & 348 & 0.842 & 0.084 & 465 & 0.216 & 148 & 0.919 & 0.022 & 0.371 & 0.216 & 49 & 0.714 & 0.301 & 0.963 & 0.210 \\
\hline Vinter & 409 & 0.782 & 0.020 & 0.517 & 0.280 & 406 & 0.966 & 0.072 & 0.523 & 0.158 & 38 & 0.605 & 0.330 & 0.812 & 0.223 \\
\hline pring & 388 & 0.802 & 0.068 & & 0.230 & 359 & 0.944 & 0.0 & 0.5 & 0.1 & 34 & 0.529 & & 01 & .604 \\
\hline ummer & 526 & 0.772 & 0.110 & 33 & 0.261 & 129 & 0.791 & 0.096 & 0.485 & 0.205 & 64 & 0.703 & 0.207 & 1.08 & .478 \\
\hline ivening & 401 & 0.581 & 0.060 & 85 & 0.356 & 3 & 1 & 0.086 & 0.057 & 0.099 & 2 & 0.500 & 1.06 & 0.433 & 0.910 \\
\hline Night & 1084 & 0.880 & 0.073 & 0.578 & 0.158 & 709 & 0.946 & 0.066 & 0.726 & 0.171 & 154 & 0.753 & 0.280 & 1.538 & 0.096 \\
\hline Morning & 16 & 0.938 & 0.083 & & & 0 & - & - & 0 & - & 0 & - & - & 0 & - \\
\hline Midday & 170 & 0.753 & 0.101 & 0.442 & 0.581 & 330 & 0.894 & 0.061 & 0.610 & 0.177 & 29 & 0.138 & 0.488 & 1.471 & 1.84 \\
\hline LWS & 722 & 0.820 & 0.135 & 0.346 & 0.183 & 260 & 0.869 & 0.129 & 0.201 & 0.117 & 97 & 0.629 & 0.351 & 0.663 & 0.391 \\
\hline MWS & 862 & 0.784 & 0.029 & 0.307 & 0.29 & 564 & 0.943 & 0.065 & 0.173 & 0.176 & 81 & 0.704 & 0.252 & 0.647 & 0.334 \\
\hline HWS & 87 & 0.713 & -0.014 & 18 & 0.387 & 218 & 0.968 & -0.013 & 0.139 & 0.231 & 7 & 0.429 & 0.704 & 1.364 & 0.709 \\
\hline Cloudy & 496 & 0.746 & 0.039 & 0.383 & 0.305 & 211 & 0.948 & 0.064 & 0.169 & 0.175 & 38 & 0.737 & 0.28 & 0.605 & 0.318 \\
\hline Clear & 725 & 0.803 & 0.093 & 0.312 & 0.238 & 472 & 0.922 & 0.085 & 0.177 & 0.151 & 92 & 0.576 & 0.353 & 0.793 & 0.463 \\
\hline EAL & 450 & 0.840 & 0.077 & 0.272 & 0.204 & 359 & 0.93 & 0.039 & 0.174 & 0.201 & 55 & 0.727 & 0.295 & 0.570 & 0.276 \\
\hline
\end{tabular}

to the U.S. atmospheric monitoring enterprise once nationwide ceilometer backscatter data become available.

Acknowledgments. This research was partially funded by the NOAA Educational Partnership Program Grants NA17AE1625 and NA17AE1623 to establish the NOAA Center for Atmospheric Sciences (NCAS) at Howard University. The research at University of Maryland, Baltimore County, was funded by a grant from the National Science Foundation (Award 1503563) and the National Atmospheric and Space Administration (NASA) Research Cooperative Agreement NNX08BA42A task. The authors acknowledge the U.S. Department of Energy, Office of Science, ARM Climate Research Facility for making such a rich dataset of atmospheric observations. The authors also acknowledge the anonymous reviewers and the journal, who provided helpful insight and valuable comments.

\section{APPENDIX}

\section{Height Comparison Data}

Table A1 provides additional ways that the ML height comparison data for the $H_{C}$ method was evaluated in the three climate regimes. In addition to the analysis by atmospheric stability and aerosol loading conditions in Table 1, the comparison results were evaluated according to season, diurnal period, wind speed amount, and sky cover. The Beaufort scale was used to determine the wind speed categories, where less than $5 \mathrm{~m} \mathrm{~s}^{-1}$ was light wind speed (LWS), greater than that but less than
$11 \mathrm{~m} \mathrm{~s}^{-1}$ was moderate wind speed (MWS), and anything greater than that was heavy wind speed (HWS). For sky conditions, elevated aerosol layers (EALs) are identified in the ceilometer backscatter return signal on days with less than 4-okta cloud cover. In addition, the table below provides the same comparison parameter tools as Table 1 with the addition of average $H_{\mathrm{RS}}$ estimate of ML height. Table A1 is being provided as a reference for users and researchers of the $H_{C}$ algorithm.

\section{REFERENCES}

Atkinson, D., B. Demoz, M. Hicks, and K. Vermeech, 2017: Investigate and validate the effectiveness of the Vaisala CL31 ceilometer algorithm at selected sites across the U.S. for the Automated Surface Observing System (ASOS) program product improvement (Phase 3). Accessed 30 January 2018, 43 pp., https://vlab.ncep.noaa.gov/group/cl31-project.

Davis, K. J., N. Gamage, C. R. Hagelberg, C. Kiemle, D. H. Lenschow, and P. P. Sullivan, 2000: An objective method for deriving atmospheric structure from airborne lidar observations. J. Atmos. Oceanic Technol., 17, 1455-1468, https://doi.org/ 10.1175/1520-0426(2000)017<1455:AOMFDA>2.0.CO;2.

Emeis, S., K. Schäfer, and C. Münkel, 2008: Surface-based remote sensing of the mixing-layer height-A review. Meteor. Z., 17, 621-630, https://doi.org/10.1127/0941-2948/2008/0312.

Hicks, M., R. Sakai, and E. Joseph, 2015: The evaluation of a new method to detect mixing layer heights using lidar observations. J. Atmos. Oceanic Technol., 32, 2041-2051, https://doi.org/ 10.1175/JTECH-D-14-00103.1.

Holben, B. N., and Coauthors, 1998: AERONET-A federated instrument network and data archive for aerosol characterization. Remote Sens. Environ., 66, 1-16, https://doi.org/10.1016/ S0034-4257(98)00031-5.

Lawrence, M., 2005: The relationship between relative humidity and the dewpoint temperature in moist air: A simple conversion and 
applications. Bull. Amer. Meteor. Soc., 86, 225-233, https:// doi.org/10.1175/BAMS-86-2-225.

Liu, S., and X. Liang, 2010: Observed diurnal cycle climatology of planetary boundary layer height. J. Climate, 23, 5790-5809, https://doi.org/10.1175/2010JCLI3552.1.

Luo, T., R. Yuan, and Z. Wang, 2014: Lidar-based remote sensing of atmospheric boundary height over land and ocean. Atmos. Meas. Tech., 7, 173-182, https://doi.org/10.5194/amt-7-173-2014.

NASA, 2017: Aerosol Robotic Network. Accessed 8 December 2017, https://aeronet.gsfc.nasa.gov.

Seibert, P., F. Beyrich, S. E. Gryning, S. Joffre, A. Rasumussen, and P. Tercier, 2000: Review and intercomparison of operational methods for the determination of the mixing height. Atmos. Environ., 34, 1001-1027, https://doi.org/10.1016/S1352-2310(99) 00349-0.
Seidel, D. J., C. O. Ao, and K. Li, 2010: Estimating climatological planetary boundary layer heights from radiosonde observations: Comparison of methods and uncertainty analysis. J. Geophys. Res., 115, D16113, https://doi.org/10.1029/2009JD013680.

Weldegaber, M. H., B. B. Demoz, L. C. Sparling, R. Hoff, and S. Chiao, 2011: Observational analysis of moisture evolution and variability in the boundary layer during the dryline on 22 May 2002. Meteor. Atmos. Phys., 110, 87-102, https://doi.org/ 10.1007/s00703-010-0109-5.

Yang, T., Z. Wang, W. Zhang, A. Gbaguidi, N. Sugiomoto, X. Wang, I. Matsui, and Y. Sun, 2017: Technical note: Boundary layer height determination from lidar for improving air pollution episode modeling: Development of new algorithm and evaluation. Atmos. Chem. Phys., 17, 6215-6225, https://doi.org/10.5194/ acp-17-6215-2017. 